\title{
Response of Extreme Hydrological Events to Climate Change in the Water Source Area for the Middle Route of South-to-North Water Diversion Project
}

\author{
Wei Yang, ${ }^{1,2}$ Liping Zhang, ${ }^{1,3}$ Lijie Shan, ${ }^{1,2}$ Xinchi Chen,, ${ }^{1,2}$ and Shaodan Chen ${ }^{1,2}$ \\ ${ }^{1}$ State Key Laboratory of Water Resources and Hydropower Engineering Science, Wuhan University, Wuhan 430072, China \\ ${ }^{2}$ Hubei Collaborative Innovation Center for Water Resources Security, Wuhan University, Wuhan 430072, China \\ ${ }^{3}$ College of Tourism Culture and Geographical Science, Huanggang Normal University, Huanggang 438000, China \\ Correspondence should be addressed to Liping Zhang; zhanglp@whu.edu.cn
}

Received 20 February 2015; Revised 15 July 2015; Accepted 30 July 2015

Academic Editor: Yongqiang Zhang

Copyright (C) 2016 Wei Yang et al. This is an open access article distributed under the Creative Commons Attribution License, which permits unrestricted use, distribution, and reproduction in any medium, provided the original work is properly cited.

\begin{abstract}
As the water source area for the middle route of China's South-to-North Water Diversion Project, the upper Hanjiang basin is of central concern for future management of the country's water resources. The upper Hanjiang is also one of the most floodprone rivers in China. This paper explores the process of extreme floods by using multivariate analysis to characterize flood and precipitation event data in combination, for historical data and simulated data from global climate models. The results suggested that the generalized extreme value and Gamma models better simulated the extreme precipitation and flood volume sequence than the generalized Pareto model for the annual maximum series, while the generalized Pareto distribution model was the best-fit model for peaks over threshold series. For the two-dimensional joint distributions of precipitation and flood volume, the Frank Copula was preferred in simulation of the annual maximum flood series whereas the Gumbel Copula was the most appropriate function to simulate the points over threshold flood series. We concluded that, compared with the traditional univariate approach, multivariate statistical analysis produced flood estimates that were more physically based and statistically sound and carried lower risk for flood design purposes.
\end{abstract}

\section{Introduction}

The impact of climate change on water resources is a matter of worldwide concern [1-3]. Global warming accelerates processes of the hydrological cycle and leads to redistribution and change in the quantity of water resources in time and space. One important implication of this is predicted increases in the frequency and intensity of extreme hydrological events, namely, droughts and floods [4]. Droughts have become more serious in the Sahara, South Africa, and eastern Asia, and floods have generally increased in America and Europe in the last few decades [5, 6]. Similar observations have been made in China [7]. As well as risks to human safety, extreme hydrological events cause economic losses, and these costs are rising exponentially [8], threatening sustainable development. There is a need then to improve the scientific understanding of trends and patterns in extreme hydrological events in the context of global climate change to inform planning for disaster protection and alleviation.

There is a large body of literature on the topic of characterizing the statistical distributions and likely future patterns of extreme hydrological events, with a few key papers highlighted below. Müller-Wohlfeil et al. [9] used a global climate model (GCM) downscaling and hydrological model to simulate extreme hydrological processes under current climate conditions and future scenarios. The impact and uncertainties of climate change on hydrology was assessed by Dessu and Melesse [10] by comparing and contrasting results across diverse GCMs, future climate scenarios, and two downscaling methods. A dramatic increase in the frequency of the heaviest precipitation events over Britain in the future was predicted by Jones and Reid [11]. Using a secondgeneration coupled global climate model under different emission scenarios and fitting a generalized extreme value 
(GEV) distribution to the data, Kharin and Zwiers [12] concluded that the probability of extreme precipitation events would increase by a factor of about 2 by the end of the twentyfirst century. For the Zhujiang basin, China, Fischer et al. [13] analyzed the precipitation extremes with four distribution functions and found GEV to be the most reliable and robust, while Wang et al. [14] applied the Gamma distribution and the Kolmogorov-Smirnov (KS) test to detect changes in extreme precipitation and extreme stream flow in southern China.

The South-to-North Water Diversion Project (SNWDP) is a major project to transfer water from the Yangtze River in the south of China to the drier northern areas suffering water deficit. The water source area for the middle route of SNWDP, the upper Hanjiang, is also known to be one of the most flood-prone rivers in China, so there are good reasons for seeking to characterize the hydrology of this basin in the context of future climate change. Zhang et al. [15] used the GEV and the generalized Pareto distribution (GPD) models to fit the extreme precipitation data in the upper reaches of the Hanjiang basin and evaluated the corresponding values for a number of return periods. The statistical relationship between the larger scale climate predictors and observed precipitation in the Hanjiang basin was investigated by Guo et al. [16]. They used a statistical downscaling method based on an artificial neural network (ANN) and predicted that precipitation in the basin would reduce in the 2020s and 2050 s and increase in 2080s. Xu et al. [17] also applied statistical downscaling to establish a coupled relationship between GCM and the HBV precipitation-runoff model in order to predict runoff in the upper reaches of the Hanjiang basin under the A2 and B2 climate scenarios. They demonstrated that floods would likely be more frequent during the period 2011 to 2100 . Most of the previous research on extreme hydrological events of the Hanjiang basin has taken a univariate approach to the analysis of flood and precipitation event data. As precipitation is the most important direct cause of flood events, we propose that new insight into the process of extreme floods can be gained by using multivariate analysis to characterize flood and precipitation event data in combination. We illustrate this approach using data from the Hanjiang but note that it has universal application.

This paper is organized as follows: Section 2 describes the study area and data used in the study; Section 3 introduces the regional frequency analysis methods and statistical probability models; Section 4 analyzes the statistical characteristics of extreme precipitation and extreme flood events based on the GEV, GPD and Gamma distribution models, and the Copula function; Section 5 predicts extreme precipitation and extreme flood events under future climate change scenarios; conclusions are presented in Section 6.

\section{Study Area and Data}

2.1. Study Area. Hanjiang, with a watershed area of $159,000 \mathrm{~km}^{2}$ and a mainstream length of $1577 \mathrm{~km}$, is the largest tributary of the Yangtze River. It originates in the south Qinling Mountains and flows through the five provinces of Shanxi, Gansu, Sichuan, Henan, and Hubei. The focus of this study

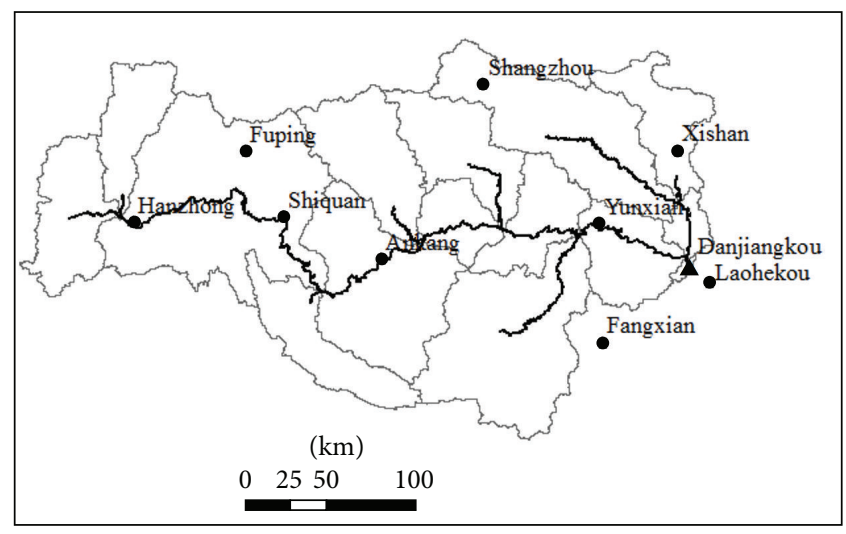

- Meteorological stations

$\Delta$ Reservoir

— Drainage network

FIGURE 1: Locations of meteorological stations and reservoir in the study area.

is the headwater area located upstream of the Danjiangkou Reservoir between $106-112^{\circ} \mathrm{E}$ and $31.4-34.1^{\circ} \mathrm{N}$. This area serves as the water source area for the middle route of SNWDP, which draws water from Danjiangkou Reservoir. In this headwater area the mainstream has a length of $925 \mathrm{~km}$ and drains a watershed area of $95,200 \mathrm{~km}^{2}$. The subtropical monsoon climate gives rise to mild and humid weather, with an annual average temperature of $14.6^{\circ} \mathrm{C}$ and mean annual precipitation of $819.5 \mathrm{~mm}$. Rainfall is unevenly distributed in the basin, declining from south to north. The precipitation is strongly seasonal, with $70 \%$ occurring between May and September. The mean annual runoff is about 368.7 billion $\mathrm{m}^{3}$ and is also strongly seasonal, being dominantly sourced from storm event surface runoff.

2.2. Meteorological and Hydrological Data. The stationobserved data used in the study included daily precipitation and daily runoff from 1969 to 2008. Daily precipitation data from 9 meteorological stations were obtained from the Shared Services Network of the China Meteorological Administration and China Hydrological Bureau. The daily inflow runoff data from Danjiangkou Reservoir were provided by the Changjiang Water Resources Commission (CWRC) (Figure 1). The areal mean precipitation was calculated with the Thiessen polygon method. Two extreme series were considered, the annual maximum (AM) series and peaks over threshold (POT) series. The AM series comprised the maximum daily precipitation in each year. The POT series comprised the daily precipitation exceeding the 98th percentile value of the data.

2.3. GCM Data. The Fourth Assessment Report of the Intergovernmental Panel on Climate Change (IPCC AR4) provides 23 GCMs which have the ability to simulate current climate over East Asia with a given degree of uncertainty [18]. In order to reduce the uncertainties of GCMs simulation of precipitation, it is common practice to adopt the coupled 
TABLE 1: The Gumbel-Hougaard, Clayton, and Frank Copula functions and model parameters.

\begin{tabular}{lll}
\hline Copula function & 2D distribution & 3D distribution \\
\hline Gumbel-Hougaard & $C(u, v)=\exp \left\{-\left[(-\ln u)^{\theta}+(-\ln v)^{\theta}\right]^{1 / \theta}\right\}$ & $C(u, v, w)=\exp \left\{-\left[(-\ln u)^{\theta}+(-\ln v)^{\theta}+(-\ln w)^{\theta}\right]^{1 / \theta}\right\}$ \\
Clayton & $C(u, v)=\left(u^{-\theta}+v^{-\theta}-1\right)^{-1 / \theta}$ & $C(u, v, w)=\left(u^{-\theta}+v^{-\theta}+w^{-\theta}-2\right)^{-1 / \theta}$ \\
Frank & $C(u, v)=-\frac{1}{\theta} \ln \left[1+\frac{\left(e^{-\theta u}-1\right)\left(e^{-\theta v}-1\right)}{e^{-\theta}-1}\right]$ & $C(u, v, w)=-\frac{1}{\theta} \ln \left[1+\frac{\left(e^{-\theta u}-1\right)\left(e^{-\theta v}-1\right)\left(e^{-\theta w}-1\right)}{\left(e^{-\theta}-1\right)^{2}}\right]$ \\
\hline
\end{tabular}

climate model rather than the single model. The relative error of the simulation results for extreme precipitation indices with the coupled climate model is smaller than with the single model [19]. However, our research focuses on extreme events, and the homogenizing effect of the coupled climate model would dilute the extremes. Therefore, the single model dataset from the World Climate Research Programme (WCRP) Coupled Model Intercomparison Project Phase 3 (CMIP3) was applied in this study. The Special Report for Emission Scenarios (SRES) [20] developed four future greenhouse gas emission scenarios on the basis of possible long-term global and regional dynamics of the 21st century, and three of them, A2 (high emission), A1B (medium emission) and B1 (low emission) [18], were selected for use in this study. The daily precipitation series from CSIRO_MK3_5, INMCM3_0, and NCAR_PCM1 GCM models were adopted.

\section{Methodology}

3.1. Extreme Value Statistical Probability Models. The Gamma, GEV, and GPD models have been widely applied in simulations of extreme hydrological events. The GEV distribution integrates three extreme distributions [21-23], including the Weibull, Gumbel, and Fréchet. As the GEV distribution is independent of the probability distribution characteristics of the original data and only samples the extreme value, it is the most direct description of extreme climate information contained within climate observation data. The Gamma distribution is the most important skewed distribution in climatological statistics, it can be used to fit normal distributions, and it shows high stability in description of precipitation [24]. In application of the POT series, the GDP is often used to describe the probability distribution of all observation data beyond a certain threshold value [25]. The POT method increases the number of measurements included in the analysis and correspondingly reduces the statistical uncertainty of quantile variances and improves the fitting accuracy. The cumulative distribution functions (CDFs) of the GEV, GPD, and Gamma distribution are expressed as

$$
\begin{aligned}
F_{\mathrm{GEV}}(x) & =\exp \left\{-\left[1+\xi\left(\frac{x-\mu}{\sigma}\right)\right]^{-1 / \xi}\right\}, \\
1+\xi\left(\frac{x-\mu}{\sigma}\right)>0 & \\
F_{\mathrm{GPD}}(x) & =1-\left[1-\xi\left(\frac{x-\mu}{\sigma}\right)\right]^{1 / \xi} \\
F_{\mathrm{Gamma}}(x) & =\frac{1}{\beta^{\alpha} \Gamma(\alpha)} \int_{0}^{x} x^{\alpha-1} e^{-x / \beta} \mathrm{d} x,
\end{aligned}
$$

where $\alpha$ and $\xi$ are shape parameters, $\beta$ and $\sigma$ are scale parameters, and $\mu$ is a location parameter.

3.2. Copula Function. The Copula function plays an important role in the study of multivariate extreme theory [2628]. The Copula function can connect joint distributions of several random variables with their marginal distributions [26]. In this study, three Copula functions, GumbelHougaard, Clayton, and Frank, were used to build a joint distribution model of precipitation and flood discharge. These functions can be described by two-dimensional (2D) and three-dimensional (3D) distributions (Table 1). In this case, the joint CDF with two or three variables can expressed as

$$
\begin{gathered}
F\left(x_{1}, x_{2}\right)=C\left(F_{X_{1}}\left(x_{1}\right), F_{X_{2}}\left(x_{2}\right)\right) \\
F\left(x_{1}, x_{2}, x_{3}\right)=C\left(F_{X_{1}}\left(x_{1}\right), F_{X_{2}}\left(x_{2}\right), F_{X_{3}}\left(x_{3}\right)\right),
\end{gathered}
$$

where $F_{X}(x)$ is the marginal CDF of each variable.

3.3. Selection of the Optimal Distribution. The KolmogorovSmirnov (KS) test was used to judge how well the presumed distributions fitted the sample data. The KS test compares the empirical cumulative distribution function of the observed series and the theoretical cumulative distribution function of the candidate distribution and then calculates the largest difference between them. Under the significance level $\alpha=$ 0.05 , if the KS test statistic $(D)$ is greater than the critical value, the hypothesis on the distributional form is rejected. The smaller the value of $D$ is, the better the assumed distribution fits the sample data.

Following common practice, the Root Mean Square Error (RMSE) criterion was used to measure the difference between values predicted by the model and the observed values. The RMSE value is defined as

$$
\mathrm{RMSE}=\sqrt{\frac{1}{n} \sum_{i=1}^{n}\left[P_{c}(i)-P_{o}(i)\right]^{2}},
$$

where $P_{c}(i)$ is actual frequency and $P_{o}(i)$ is theoretical frequency.

3.4. Return Periods. A return period is an estimate of the average time between rainfall or flood events of a given 
magnitude. The return periods for variables greater than (or equal to) a specific value are usually determined as

$$
T(x)=\frac{1}{1-F_{X}(x)} .
$$

For bivariate distributions, the probability that both $x_{1}$ and $x_{2}$ exceed certain thresholds can be derived in terms of Copulas:

$$
\begin{aligned}
P\left(X_{1} \geq x_{1}, X_{2} \geq x_{2}\right)= & 1-F_{X_{1}}\left(x_{1}\right)-F_{X_{2}}\left(x_{2}\right) \\
& +C\left(F_{X_{1}}\left(x_{1}\right), F_{X_{2}}\left(x_{2}\right)\right) .
\end{aligned}
$$

For the 3D distribution, the joint return periods can be expressed as

$$
\begin{aligned}
T\left(x_{1}, x_{2}, x_{3}\right) & =\frac{1}{P\left(X_{1} \geq x_{1} \cap X_{2} \geq x_{2} \cap X_{3} \geq x_{3}\right)} \\
& =\frac{1}{1-F_{X_{1}}-F_{X_{2}}-F_{X_{3}}+C\left(F_{X_{1}}, F_{X_{2}}\right)+C\left(F_{X_{1}}, F_{X_{3}}\right)+C\left(F_{X_{2}}, F_{X_{3}}\right)-C\left(F_{X_{1}}, F_{X_{2}}, F_{X_{3}}\right)}
\end{aligned}
$$

\subsection{Mann-Kendall Tests for Trend and Change Point in Time} Series. The Mann-Kendall (MK) test is a nonparametric method of detecting monotonic trend in a data series $[29,30]$. As the MK method does not require the data to conform to any particular distribution and is less sensitive to outliers, it has been widely applied to hydrological data, which rarely follows a normal distribution. The data should not be serially correlated, so for this study the data were first prewhitened [31].

For a time series $\left\{x_{i} ; i=1,2, \ldots, n\right\}$, the test statistic $S$ is defined as

$$
\begin{aligned}
S & =\sum_{i=1}^{n-1} \sum_{j=i+1}^{n} \operatorname{sgn}\left(x_{j}-x_{i}\right), \\
\operatorname{sgn}\left(x_{j}-x_{i}\right) & = \begin{cases}1 & x_{i}<x_{j} \\
0 & x_{i}=x_{j} \\
-1 & x_{i}>x_{j} .\end{cases}
\end{aligned}
$$

When $n \geq 10$, the distribution of $S$ approaches a normal distribution, and the mean and variance of $S$ are given as

$$
\begin{aligned}
E(S) & =0, \\
\operatorname{Var}(S) & =\frac{n(n-1)(2 n+5)}{18} .
\end{aligned}
$$

The normalized test statistic $Z$ is calculated as

$$
Z= \begin{cases}\frac{S-1}{\sqrt{\operatorname{Var}(S)}} & S>0 \\ 0 & S=0 \\ \frac{S+1}{\sqrt{\operatorname{Var}(S)}} & S<0 .\end{cases}
$$

In a two-side trend test, the null hypothesis of no trend is rejected if $|Z|>Z_{1-\alpha / 2}$ at the $\alpha$ level of significance $(\alpha=$
$5 \%$ in this study). A positive $Z$ shows increasing trend and a negative $Z$ shows decreasing trend.

The sequential version of Mann-Kendall test [32] is used to test assumptions about the start of a trend within a sample based on rank series of progressive and retrograde rows of the sample. The sequential MK test is therefore useful for detecting abrupt change points in a hydrological series [33, 34]. For a time series $\left\{x_{i} ; i=1,2, \ldots, n\right\}$, the rank series $S_{k}$ is defined as

$$
\begin{aligned}
& S_{k}=\sum_{i=1}^{k} r_{i} \quad(k=2,3, \ldots, n), \\
& r_{i}=\left\{\begin{array}{ll}
1 & x_{i}>x_{j} \\
0 & x_{i} \leq x_{j}
\end{array} \quad(j=1,2, \ldots, i) .\right.
\end{aligned}
$$

The mean and variance of $S_{k}$ are given as

$$
\begin{aligned}
E\left(S_{k}\right) & =\frac{n(n+1)}{4}, \\
\operatorname{Var}\left(S_{k}\right) & =\frac{n(n-1)(2 n+5)}{72} .
\end{aligned}
$$

Under the assumption that the time sequences are independent, the normalized test statistic $U F_{k}$ is defined as

$$
U F_{k}=\frac{S_{k}-E\left(S_{k}\right)}{\sqrt{\operatorname{Var}\left(S_{k}\right)}} \quad(k=1,2, \ldots, n)
$$

which is the forward sequence, and the backward sequence $U B_{k}$ is calculated using the same equation but in the reverse data series. $U F_{1}=0$, and the distribution of $U F_{k}$ approaches a normal distribution. If $U F_{k}>0$, the trend is increasing with time, and if $U F_{k}<0$, the trend is decreasing with time. The calculated $U F_{k}$ value is compared with the standard normal distribution table with two-tailed confidence levels. If 
TABLE 2: The KS test statistic $D$ value of marginal distribution models.

\begin{tabular}{lcccccc}
\hline \multirow{2}{*}{ Variable } & \multicolumn{3}{c}{$D$ for AM series } & \multicolumn{3}{c}{$D$ for POT series } \\
& GEV & GPD & Gamma & GEV & GPD & Gamma \\
\hline RX1day & 0.0775 & 0.1251 & 0.0702 & 0.0850 & 0.0465 & 0.0894 \\
RX3day & 0.0840 & 0.0741 & 0.0737 & 0.0717 & 0.0649 & 0.0822 \\
W1 & 0.0867 & 0.1138 & 0.0815 & 0.0626 & 0.0645 & 0.0984 \\
W3 & 0.0965 & 0.0924 & 0.0975 & 0.1371 & 0.0635 & 0.0904 \\
\hline
\end{tabular}

$\left|U F_{k}\right|>U_{\alpha / 2}$, the trend is statistically significant; otherwise, the trend is not significant. The sequential MK test enables detection of the approximate beginning of a developing trend from the intersection point of the curves $U F_{k}$ and $U B_{k}$ of the test statistic. If the intersection point is significant at $\alpha=0.05$, then the critical point of change is at that period $[35,36]$.

\section{Statistical Characteristics of Extreme Hydrological Events}

4.1. Univariate Frequency Analysis of Extreme Hydrological Events. The maximum 1-day precipitation (RXlday) series, maximum 3-day precipitation (RX3day) series, maximum 1day flood discharge (W1) series, and maximum 3-days flood discharge (W3) series were established for the upper reaches of the Hanjiang basin by the AM and POT methods. The GEV, GPD, and Gamma models were selected for fitting of the series. The KS test statistic $D$ was less than the critical value $0.21(\alpha<0.05)$ for the three models, suggesting that all were an adequate fit (Table 2). For the AM series, the Gamma model was the best-fit model for RX1day, RX3day, and W1 series, while GPD model was optimal for the W3 series. As a whole, the GEV and Gamma models better simulated the AM series than did the GPD model. For the POT series, the GPD model was the best fit for three of the four series (Table 2).

Estimated extreme precipitation and flood discharge associated with return periods of $10,50,100,500$, and 1000 years were calculated by these three distribution models for the AM and POT series (Table 3). The results indicated that, for AM series, for recurrence intervals $\geq 50$ years, values of precipitation and flood discharge estimated by GPD model were noticeably lower than those by GEV and Gamma models. These lower values would translate to a higher risk for flood planning so GDP was regarded as unsuitable for the AM series. For the POT series, values estimated by GEV model were higher than those by GPD and Gamma models, and the values were distant from the observed data, indicating that GEV was unsuitable for the POT series (Table 3). For the AM series, the values calculated by Gamma distribution model indicated slightly higher values series than for the POT series. Adopting the more conservative estimates of the AM series would provide lower risk for flood planning.

4.2. Multivariate Frequency Analysis of Extreme Hydrological Events. The Kendall tau rank correlation coefficient and the Spearman's rank correlation coefficient were used to analyze the degree of bivariate correlation between pairs of RX1day, RX3day, W1, and W3 for the AM and POT series (Table 4). There were significant positive correlations between extreme precipitation and extreme flood discharge, allowing the possibility of building a joint distribution model of precipitation and flood discharge using Copula functions.

Two-dimensional joint distributions were established based on the Gumbel-Hougaard, Clayton, and Frank Copula functions. The KS test and RMSE criterion suggested that the Frank Copula was superior for simulation of the AM series and the corresponding GEV distribution, while the GumbelHougaard Copula was superior for simulation of the POT series and the corresponding GPD model (Table 5). All the values of the KS test statistic $D$ of the optimal functions were smaller than the critical value of 0.21 under the significant level of $\alpha=0.05$, demonstrating that the simulations passed the KS test.

The 2D Frank Copula (Figure 2) and Gumbel-Hougaard Copula (Figure 3) functions both displayed highly significant correlation between the empirical and theoretical frequencies. For the AM series, the correlation coefficient for RXldayW1, RX1day-W3, RX3day-W1, and RX3day-W3 were 0.986, $0.989,0.991$, and 0.991 , respectively, demonstrating that the Frank Copula function was a good fit to the AM samples. For the POT series, the correlation coefficient for RXldayW1, RX1day-W3, RX3day-W1, and RX3day-W3 were 0.992, $0.995,0.994$, and 0.993 , respectively, demonstrating that the Gumbel-Hougaard Copula function was a good fit to the POT samples and could be used to build the 2D joint distributions of precipitation and flood discharge.

Extreme precipitation and flood discharge under the return periods of $10,20,50,100,200,500$, and 1000 years were estimated using the 2D joint distributions (Figure 4). It was assumed that the frequency of precipitation and floods were the same. The notation used to describe the joint distributions was that, for example, "AM, RX1day-W1" represents that the variables of the ordinate were calculated via joint distributions of RX1day and W1 from the AM series, and so on (Figure 4).

Similar to the 2D joint distributions, 3D joint distributions were established based on the Gumbel, Clayton, and Frank Copula functions. The Frank Copula was the best-fit function for both the AM and POT series. Extreme precipitation and flood volume under the return periods of 10, 20, 50, 100, 200, 500, and 1000 years were estimated (Figure 5). The notation used to describe the joint distributions was that, for example, "AM, RX1day-W1-W3" represents that the variables of the ordinate were calculated by joint distributions of RX1day, W1, and W3 from the AM series, and so on (Figure 5).

The estimated extreme precipitation rates and flood discharges for the AM series were larger than those for the POT series under the same return period (Figures 4 and 5). Also, the estimated extreme value of the POT series did not increase with increasing return period to the same extent as the AM series. It appears that the Copula function and the corresponding GPD model for the POT series was unsuitable for estimating the extreme value under large return periods because of the limited extreme sample of the POT series. This result suggests that the AM series better described the 
TABLE 3: Extreme precipitation and flood discharge estimated via marginal distribution models for a range of return periods.

\begin{tabular}{|c|c|c|c|c|c|c|c|c|c|c|c|c|}
\hline \multirow{3}{*}{ Return periods (year) } & \multicolumn{12}{|c|}{ AM series } \\
\hline & \multicolumn{3}{|c|}{ RX1day (mm/d) } & \multicolumn{3}{|c|}{ RX3day (mm/3 d) } & \multicolumn{3}{|c|}{$\mathrm{W} 1\left(\times 10^{9} \mathrm{~m}^{3} / \mathrm{d}\right)$} & \multicolumn{3}{|c|}{$\mathrm{W} 3\left(\times 10^{9} \mathrm{~m}^{3} / 3 \mathrm{~d}\right)$} \\
\hline & Gamma & GEV & GPD & Gamma & GEV & GPD & Gamma & GEV & GPD & Gamma & GEV & GPD \\
\hline 10 & 55.6 & 55.2 & 59.9 & 96.4 & 95.9 & 100.2 & 2.000 & 1.964 & 2.107 & 4.323 & 4.270 & 4.533 \\
\hline 50 & 72.3 & 70.9 & 71.6 & 123.0 & 127.9 & 117.1 & 2.796 & 2.693 & 2.500 & 6.001 & 5.866 & 5.233 \\
\hline 100 & 78.9 & 76.8 & 74.3 & 133.4 & 141.5 & 120.9 & 3.117 & 2.982 & 2.581 & 6.677 & 6.505 & 5.364 \\
\hline 500 & 93.3 & 89.2 & 77.8 & 156.0 & 173.1 & 125.9 & 3.834 & 3.610 & 2.678 & 8.183 & 7.906 & 5.508 \\
\hline \multirow[t]{2}{*}{1000} & 99.2 & 93.9 & 78.7 & 165.3 & 186.8 & 127.0 & 4.134 & 3.863 & 2.697 & 8.811 & 8.477 & 5.535 \\
\hline & \multicolumn{12}{|c|}{ POT series } \\
\hline \multirow[t]{2}{*}{ Return periods (year) } & \multicolumn{3}{|c|}{ RX1day $(\mathrm{mm} / \mathrm{d})$} & \multicolumn{3}{|c|}{$\mathrm{RX} 3$ day $(\mathrm{mm} / 3 \mathrm{~d})$} & \multicolumn{3}{|c|}{$\mathrm{W} 1\left(\times 10^{9} \mathrm{~m}^{3} / \mathrm{d}\right)$} & \multicolumn{3}{|c|}{ W3 $\left(\times 10^{9} \mathrm{~m}^{3} / 3 \mathrm{~d}\right)$} \\
\hline & Gamma & GEV & GPD & Gamma & GEV & GPD & Gamma & GEV & GPD & Gamma & GEV & GPD \\
\hline 10 & 50.5 & 51.3 & 52.1 & 88.1 & 88.3 & 91.4 & 1.753 & 1.763 & 1.785 & 3.945 & 4.391 & 4.071 \\
\hline 50 & 63.1 & 77.0 & 65.3 & 110.4 & 119.9 & 105.4 & 2.328 & 3.050 & 2.366 & 5.236 & 6.915 & 5.451 \\
\hline 100 & 68.0 & 91.0 & 69.4 & 119.0 & 134.3 & 108.5 & 2.556 & 3.839 & 2.562 & 5.747 & 8.265 & 5.919 \\
\hline 500 & 78.6 & 133.1 & 76.5 & 137.8 & 169.9 & 112.5 & 3.059 & 6.517 & 2.920 & 6.875 & 12.229 & 6.783 \\
\hline 1000 & 83.0 & 156.3 & 78.8 & 145.5 & 186.3 & 113.3 & 3.267 & 8.176 & 3.041 & 7.342 & 14.377 & 7.077 \\
\hline
\end{tabular}

TABLE 4: Correlation coefficient of the different extreme samples.

\begin{tabular}{lcccc}
\hline Variables & \multicolumn{2}{c}{ AM series } & \multicolumn{2}{c}{ POT series } \\
\hline RX1day-W1 & $\tau$ & $\rho$ & 0.40 & 0.57 \\
RX1day-W3 & 0.32 & 0.48 & 0.33 & 0.49 \\
RX3day-W1 & 0.31 & 0.47 & 0.43 & 0.59 \\
RX3day-W3 & 0.37 & 0.54 & 0.42 & 0.59 \\
\hline
\end{tabular}

Note: $\tau$ is the Kendall coefficient; $\rho$ is the Spearman's coefficient. RX1day-W1 represents the joint distribution of RX1day and W1.

TABLE 5: Optimal function and evaluation indicators of 2D joint distribution for AM and POT series.

\begin{tabular}{|c|c|c|c|c|c|c|}
\hline \multirow{2}{*}{ Variables } & \multicolumn{3}{|c|}{ AM series } & \multicolumn{3}{|c|}{ POT series } \\
\hline & Copula function & RMSE & $D$ & Copula function & RMSE & $D$ \\
\hline RX1day-W1 & Frank & 0.0395 & 0.0893 & Gumbel & 0.0255 & 0.0815 \\
\hline RX1day-W3 & Frank & 0.0356 & 0.0999 & Gumbel & 0.0221 & 0.0659 \\
\hline RX3day-W1 & Frank & 0.0341 & 0.0996 & Gumbel & 0.0220 & 0.0582 \\
\hline RX3day-W3 & Frank & 0.0350 & 0.0938 & Gumbel & 0.0260 & 0.0652 \\
\hline
\end{tabular}

extreme hydrological events for the purpose of lower risk flood planning.

The design floods of Danjiangkou Reservoir dam used in the preliminary design stage, calculated by a traditional single distribution hydrological method [37], were compared with the design value of W1 under a range of return periods calculated by $2 \mathrm{D}$ and 3D Copula functions for the AM series (Table 6). The design value calculated by the $3 \mathrm{D}$ Copula function was the highest of these for all return periods. The design values calculated by the $2 \mathrm{D}$ Copula function were slightly larger than the ones used in the preliminary dam design stage for 10-, 20-, and 1000-year return periods, while 2D Copula function estimates were slightly lower than preliminary dam design estimates for 50- and 100year return periods. The joint distribution makes more use of available extreme information than a traditional single distribution model, and the higher estimates of flood peaks given by the joint distribution are more conservative for application to flood planning. Overall, the results of the multivariate frequency analysis suggests that, in the case of the upper Hanjiang, this approach to describing extreme floods would lead to more conservative (lower risk) design than a traditional approach.

\section{Prediction of Extreme Hydrological Events under Future Climate Change Scenarios}

5.1. Simulation of Precipitation in the Baseline Period. Of the 23 GCMs of IPCC AR4, after excluding the models with incomplete daily precipitation series under $A 1 B, A 2$, and B1 climate scenarios, the three models CSIRO_MK3_5, 


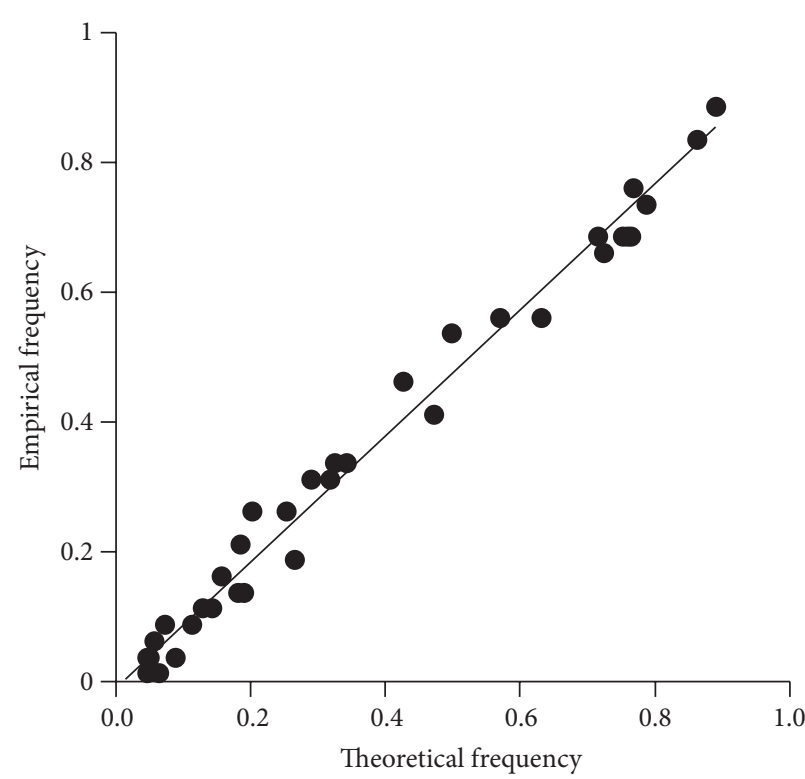

(a)

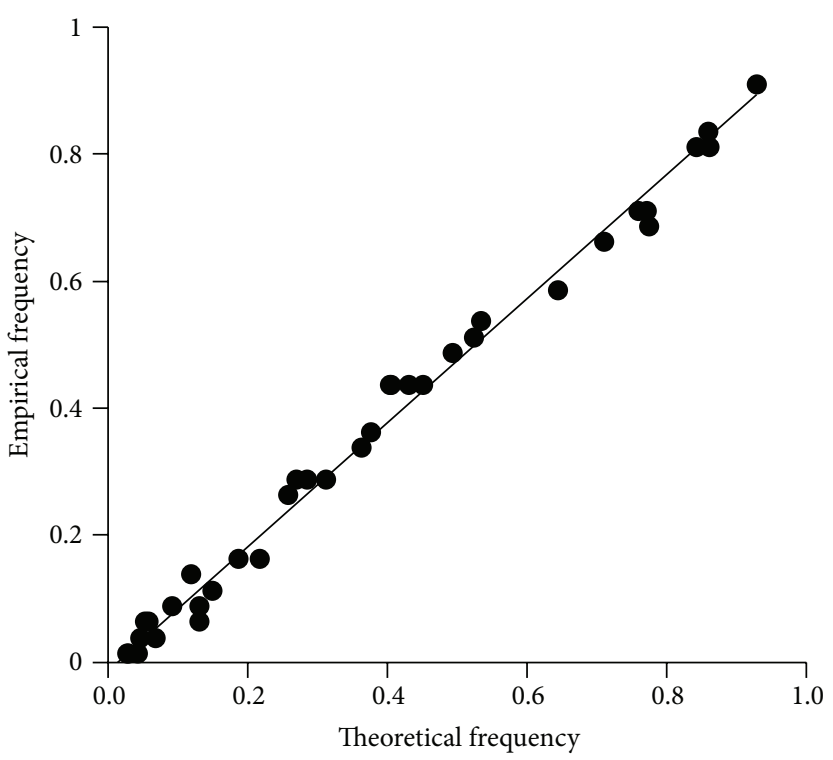

(c)

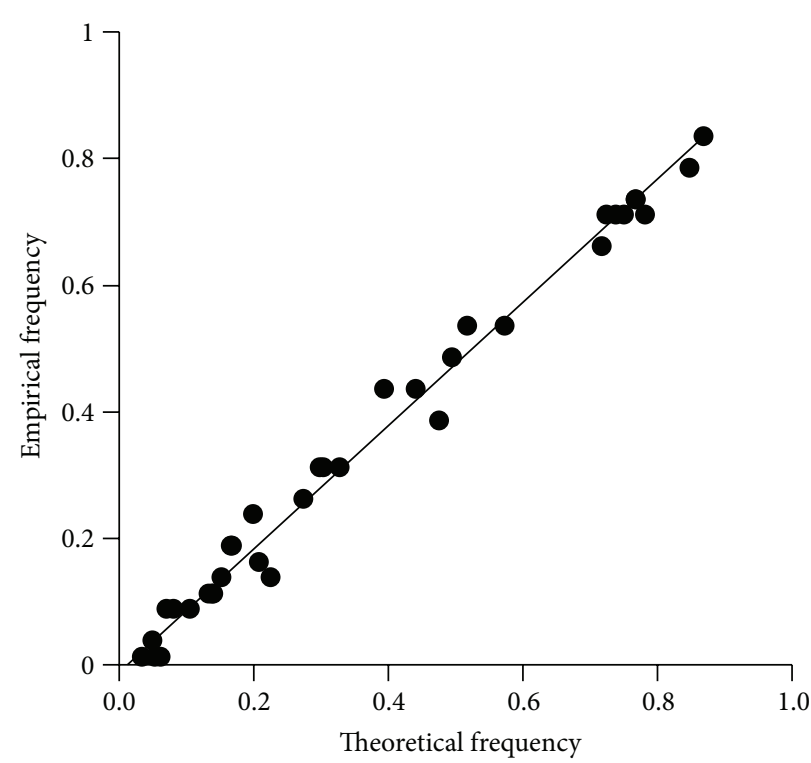

(b)

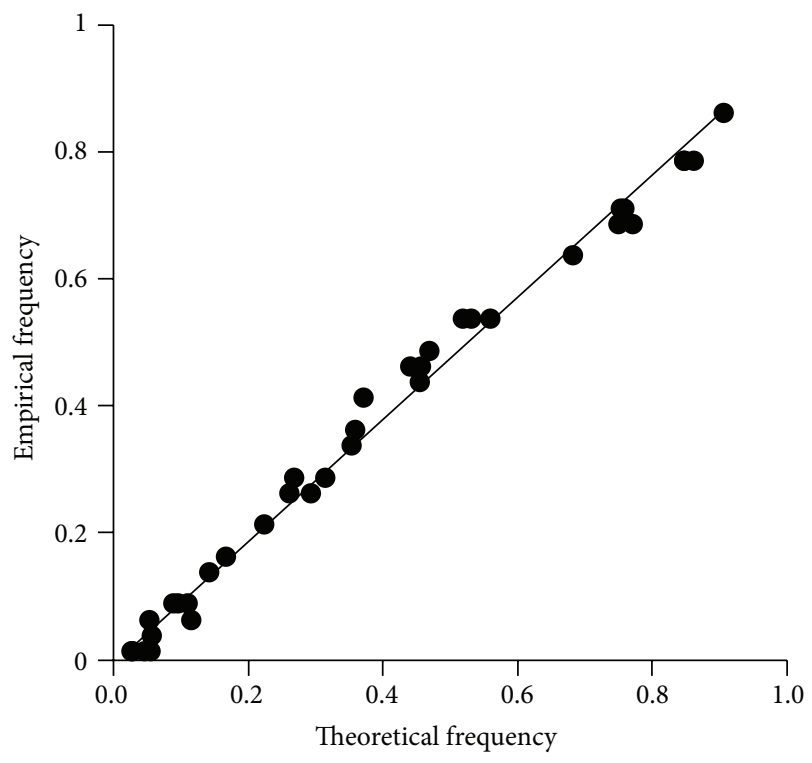

(d)

FIGURE 2: Empirical and theoretical frequency of 2D Frank Copula function joint distribution for different combination of the AM series: (a) X1day-W1, (b) RX1day-W3, (c) RX3day-W1, and (d) RX3day-W3.

INMCM3_0, and NCAR_PCM1, having complete daily outputs of precipitation data, were utilized for this study. Observed daily precipitation data in the baseline period (1961-2000) was used to assess the capability of these three GCMs in simulating the historical precipitation. Precipitation in the example years 1970, 1980, 1990, and 2000 and the total precipitation over the 40 years of the baseline period were used for comparison (Table 7). For the simulation of the total precipitation over 40 years, the errors of three models CSIRO_MK3_5, INMCM3_0, and NCAR_PCM1 were $3.65 \%, 88.69 \%$, and $70.05 \%$, respectively. As well as closely predicting the 40-year total precipitation, the CSIRO_MK3_5 model also closely predicted annual precipitation for the four example years, while the other two models were highly inferior (Table 7). This result is in agreement with previous work that has demonstrated the capacity of CSIRO_MK3_5 to simulate the contemporary climate of China [38, 39]. On this basis, the CSIRO_MK3_5 was chosen to simulate hydrological events in the study area under future climate change scenarios.

The annual precipitation series over the baseline period simulated by the CSIRO_MK3_5 model fitted the observed pattern of annual precipitation reasonably well, with both series having negative trend (Figure 6). However, the rate 


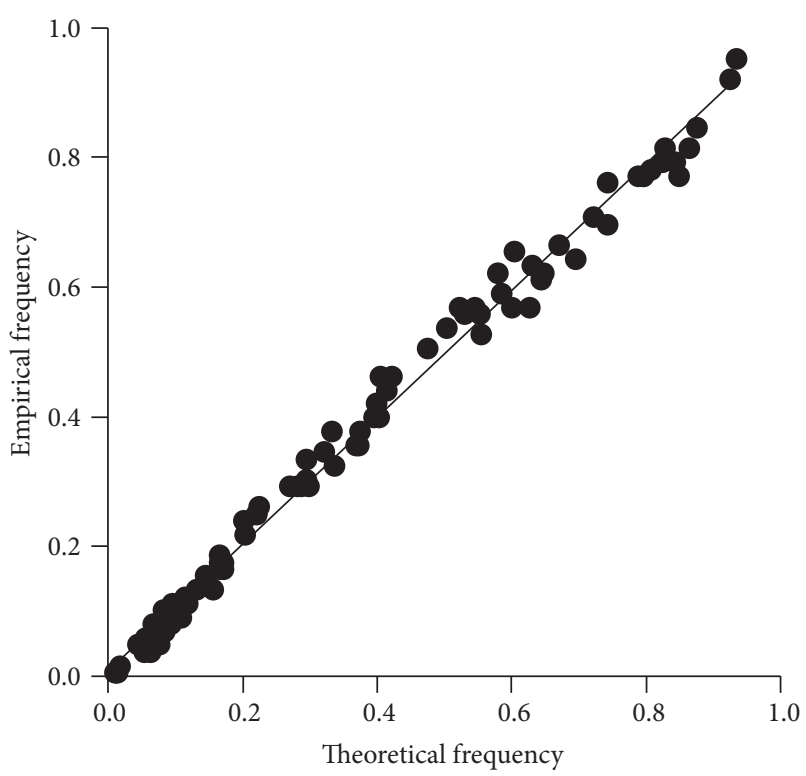

(a)

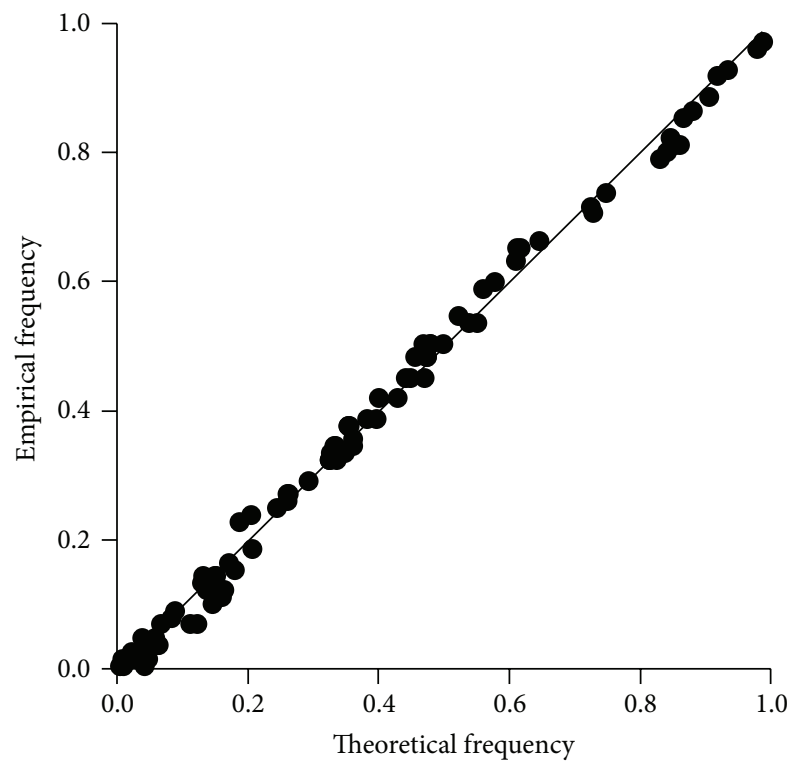

(c)

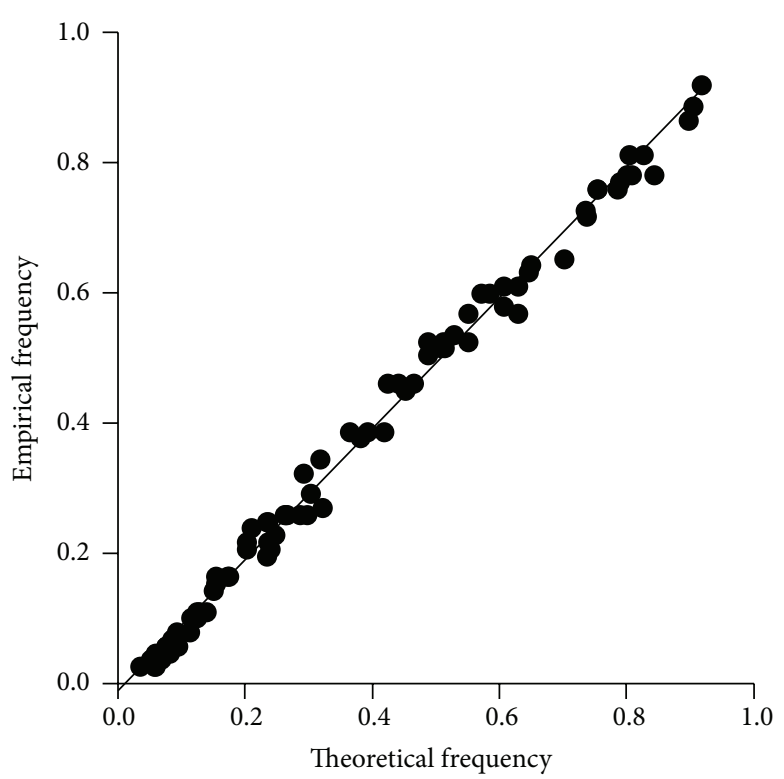

(b)

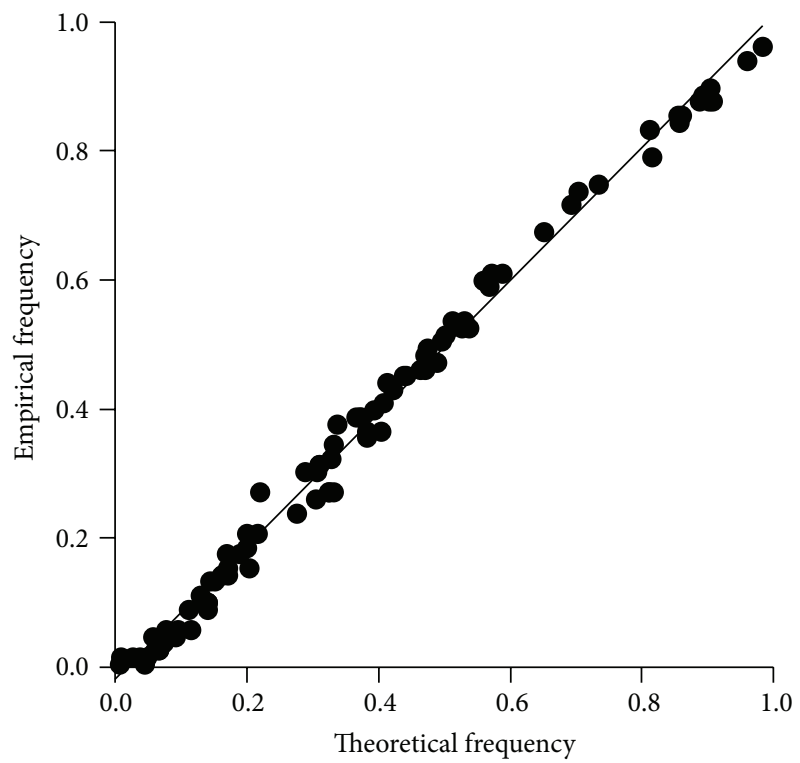

(d)

FIGURE 3: Empirical and theoretical frequency of 2D Gumbel Copula function joint distribution for different combination of the POT series: (a) RX1day-W1, (b) RX1day-W3, (c) RX3day-W1, and (d) RX3day-W3.

of decline in precipitation over time was greater for the simulated data, and there were years with large differences between observed and simulated precipitation, highlighting uncertainties in the CSIRO_MK3_5 simulation that transferred unavoidable uncertainty to our results.

5.2. Trends in Simulated Future Annual Precipitation. Simulated future precipitation over the period 2016 to 2100 (Figure 7) did not have significant trend under the A1B, A2, and $\mathrm{B} 1$ scenarios (the values of $\mathrm{MK}$ trend test statistic $Z$ were $-0.467,-0.034$, and 0.793 , resp.). The results of sequential MK test statistic were shown in Figure 8. Under the A1B scenario, yearly plots of $U F_{k}$ had no significant change, and the $U F_{k}$ and
$U B_{k}$ curves displayed several points of intersection, but all the change points were insignificant for this scenario. Under the A2 scenario, $U F_{k}$ spots indicated a decreasing trend of precipitation over the considered periods, especially during the periods from 2045 to 2075, but no significant change points were found. The precipitation trend characteristics under the B1 scenario were similar to that under the $\mathrm{A} 1 \mathrm{~B}$ scenario; the $U F_{k}$ and $U B_{k}$ plots intersected each other for several times signifying no recognizable trend in the time series.

5.3. Trends in Simulated Future Extreme Precipitation. The AM series RX1day and RX3day (Figure 9) were selected to 

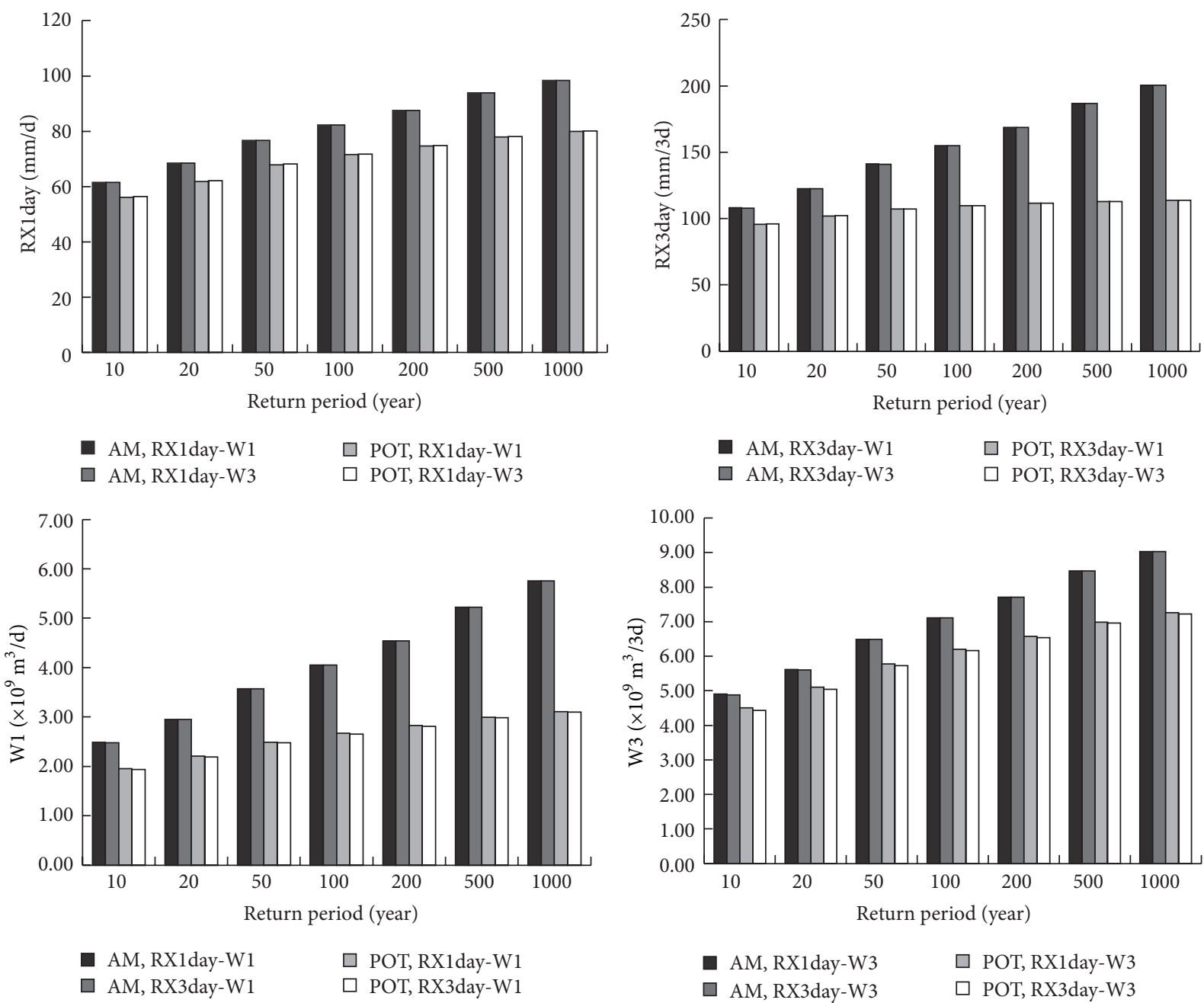

FIGURE 4: Extreme precipitation and flood discharge estimated via 2D joint distributions under a range of return periods.

test for trend in future extreme precipitation under the three climate change scenarios. The $Z$ values of RX1day were 2.152, 2.167, and 1.454 for $\mathrm{A} 1 \mathrm{~B}, \mathrm{~A} 2$, and $\mathrm{B} 1$ scenarios, respectively, indicating an increasing trend of RXlday series under each scenario, and the trend was significant under $\mathrm{A} 1 \mathrm{~B}$ and $\mathrm{A} 2$ scenarios. The $Z$ values of RX3day were $1.37,1.438$, and 0.452 for A1B, A2, and B1 scenarios, respectively, indicating increasing trend but the trend was not significant.

The results of sequential MK test statistic (Figure 10) indicated a similar pattern over time for the three climate change scenarios. The $U F_{k}$ curves showed an increasing trend over the considered periods, and the $U B_{k}$ curves indicated a decreasing trend. Under the AlB scenarios, the sequential version of MK test for RX1day series indicated a change point in 2053 (Figure 10(a)), and the $U F_{k}$ also displayed that RX1day had shown an increasing trend since 2053. The $U F_{k}$ and $U B_{k}$ plots for RX3day series intersected each other several times (Figure 10(b)), but only 2046 can be recognized as a change point. Under the A2 scenarios, both RX1day and RX3day series had a change point in 2072, and the extreme precipitation showed a decreasing trend from 2016 till 2072 and afterward it had increased. Under the B1 scenarios, the $U F_{k}$ and $U B_{k}$ plots indicated that the change points of RXlday series were detected in 2025 and 2085, and the change points of RX3day series occurred in 2030 and 2075. Future precipitation had no significant trend under the three climate change scenarios (Figure 8), but the extreme precipitation had an increasing trend in most years (Figure 10), indicating that the proportion of the extreme precipitation in total precipitation increased constantly.

5.4. Change Trends of Future Extreme Flood. It was assumed that the frequencies of extreme precipitation and extreme flood are the same. Based on the Frank Copula function, the joint probability of precipitation and flood was calculated by the probability of future precipitation. This was used to represent the probability of floods in order to calculate the future 1-day (W1) and 3-day (W3) flood discharges via the marginal distribution function of flood volume. The future extreme flood discharge time series obtained for the AM series of RX1day and RX3day under the A1B, A2, and B1 scenarios indicated that future extreme flood volumes were 

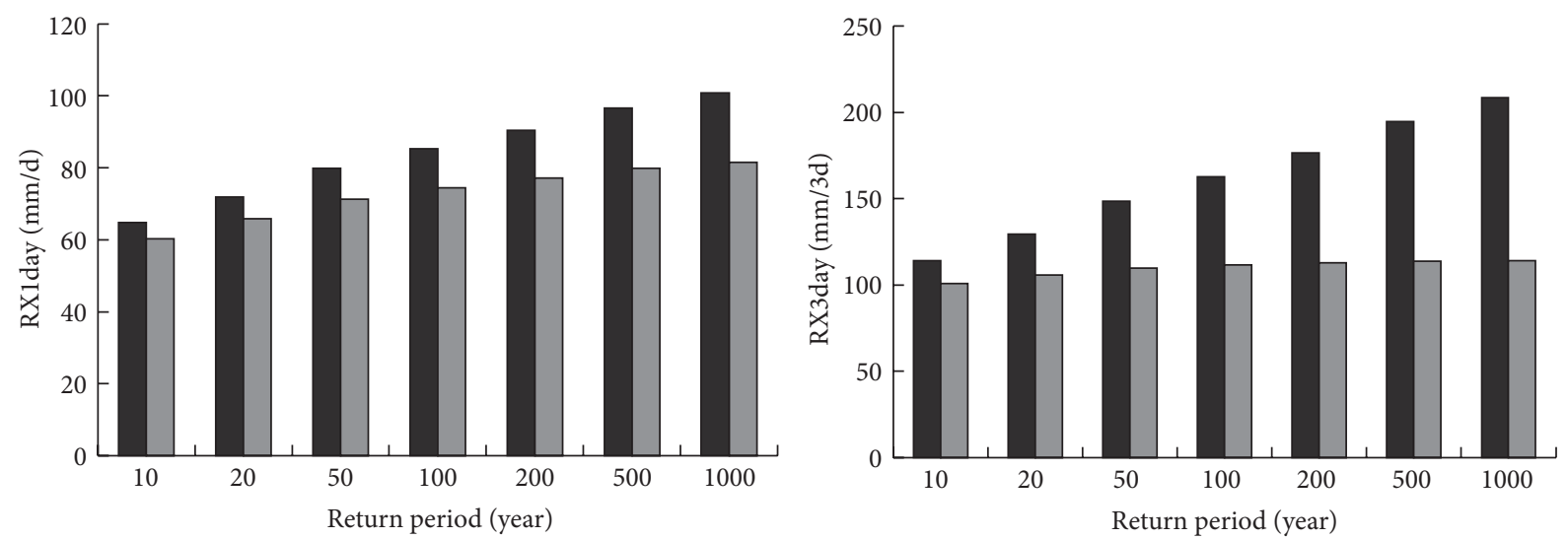

- AM, RX1day-W1-W3

$\square$ POT, RX1day-W1-W3

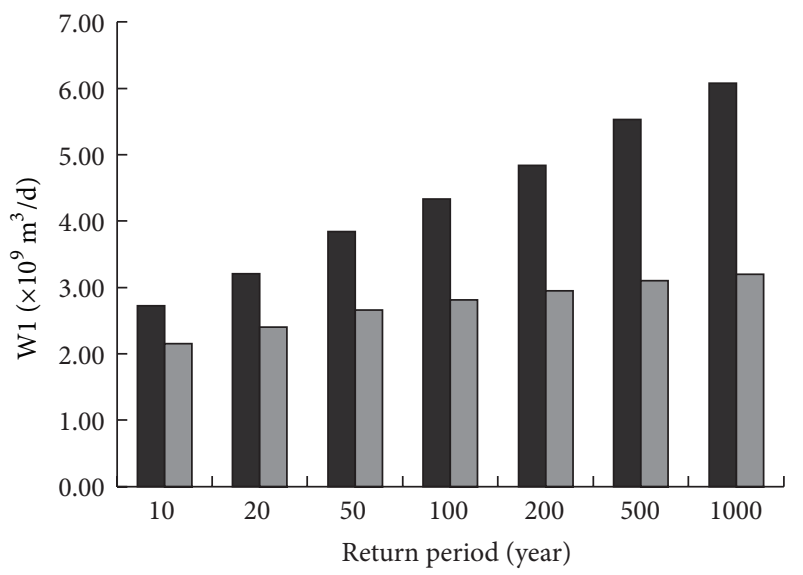

- AM, RX3day-W1-W3

$\square$ POT, RX3day-W1-W3

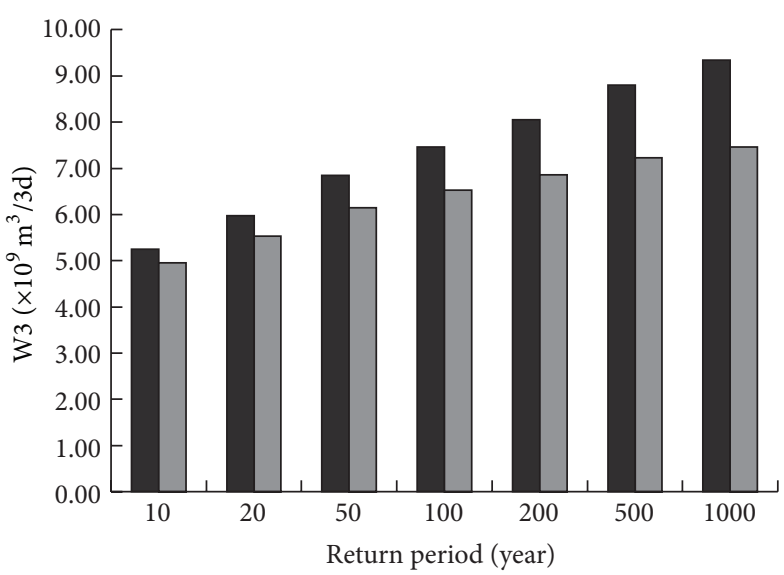

- AM, RX1day-RX3day-W1

$\square$ POT, RX1day-RX3day-W1

- AM, RX1day-RX3day-W3

$\square$ POT, RX1day-RX3day-W3

FIGURE 5: Extreme precipitation and flood discharge estimated via 3D joint distributions under a range of return periods.

TABLE 6: The design flood calculated by different methods under a range of return periods.

\begin{tabular}{lcccr}
\hline Method & \multicolumn{3}{c}{ Return period (year) } \\
& 10 & 20 & 50 & 100 \\
\hline The dam site design flood $\left(\times 10^{9} \mathrm{~m}^{3} / \mathrm{d}\right)$ & 2.445 & 2.946 & 3.577 & 4.069 \\
2D Copula function $\left(\times 10^{9} \mathrm{~m}^{3} / \mathrm{d}\right)$ & 2.492 & 2.955 & 3.568 & 5.616 \\
3D Copula function $\left(\times 10^{9} \mathrm{~m}^{3} / \mathrm{d}\right)$ & 2.697 & 3.191 & 3.835 & 4.050 \\
\hline
\end{tabular}

TABLE 7: Comparison of simulated and observed annual precipitation in the study area.

\begin{tabular}{lcccc}
\hline Year & Observed precipitation $(\mathrm{mm})$ & \multicolumn{2}{c}{ GCM simulated precipitation (mm) } \\
& & CSIRO_MK3_5 & INMCM3_0 & NCAR_PCM1 \\
\hline 1970 & 800 & 866 & 1892 & 1600 \\
1980 & 972 & 1046 & 1590 & 1376 \\
1990 & 810 & 592 & 1727 & 1244 \\
2000 & 850 & 814 & 62736 & 1324 \\
\hline 40 years & 33248 & 34462 & 56535 \\
\hline
\end{tabular}


TABLE 8: Future and historical predicted extreme flood discharges for a range of return periods.

\begin{tabular}{lccccr}
\hline Return period (year) & 5 & 10 & 20 & 30 & 40 \\
\hline Historical flood $\left(\times 10^{9} \mathrm{~m}^{3} / \mathrm{d}\right)$ & & & & & \\
W1 & 1.610 & 1.964 & 2.289 & 2.471 & 2.597 \\
W3 & 3.504 & 4.270 & 4.980 & 5.379 & 5.655 \\
Calculated by RX1day $\left(\times 10^{9} \mathrm{~m}^{3} / \mathrm{d}\right)$ & & & & \\
W1 & 1.367 & 1.754 & 2.149 & 2.388 & 2.561 \\
W3 & 2.926 & 3.651 & 4.343 & 4.739 & 5.017 \\
Calculated by RX3day $\left(\times 10^{9} \mathrm{~m}^{3} / \mathrm{d}\right)$ & & & & 5.230 \\
W1 & 1.387 & 1.768 & 2.158 & 2.394 & 2.566 \\
W3 & 2.989 & 3.692 & 4.368 & 4.756 & 5.030 \\
\hline
\end{tabular}

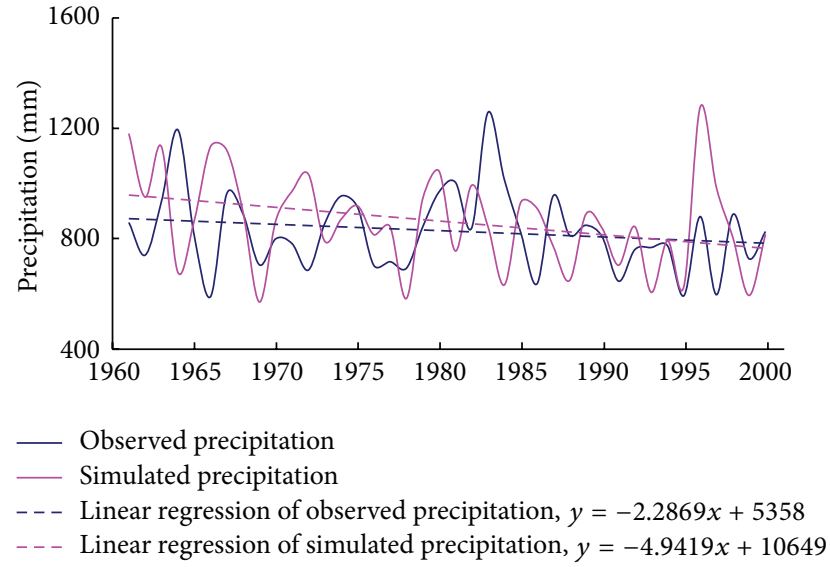

FIGURE 6: Comparison of simulated and observed annual precipitation in the study area.

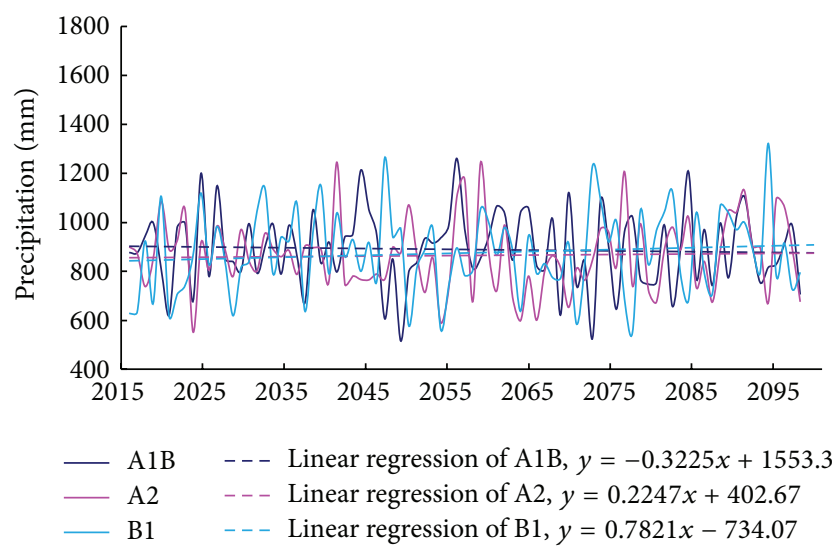

Figure 7: Annual precipitation changes from 2016 to 2100 under three climate change scenarios.

larger under the A2 scenarios than under the A1B and B1 scenarios (Figure 11).

The future extreme 1-day (W1) and 3-day (W3) flood discharges calculated from precipitation for a range of return periods were slightly smaller than the corresponding values calculated from the historical data (Table 8). This was consistent with the results of the previous research [40].

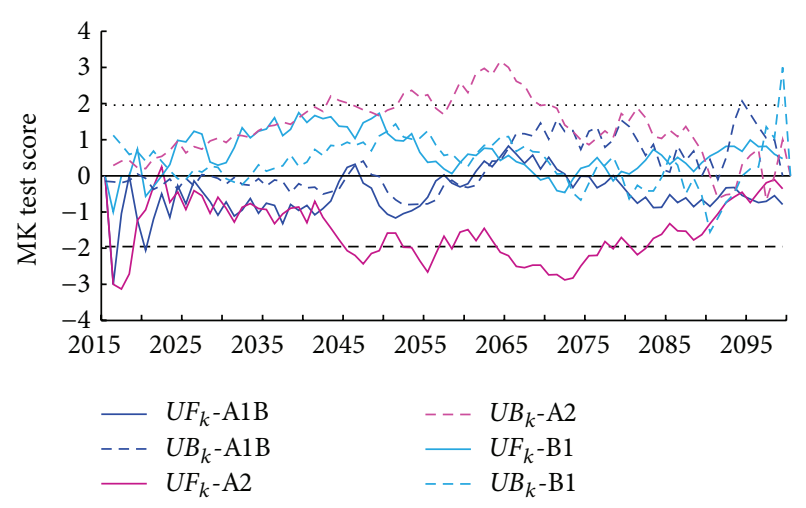

FIGURE 8: MK test score for annual precipitation from 2016 to 2100 under three climate change scenarios.

In China, the convention is to classify floods by size according to return period: (1) small, having a return period less than 5 years; (2) medium, having a return period between 5 and 20 years; (3) large, having a return period longer than 20 years. The frequencies of occurrence of floods of the three conventional size grades under the A1B, A2, and B1 scenarios (Figure 12) indicate that under the future scenarios small floods would occur less frequently than under historical conditions, while the frequency of occurrence of the medium floods and large floods under the future scenarios would be higher than the observed frequency of occurrence. Also, the frequency of occurrence of large floods under the A2 scenario was higher than that under the $\mathrm{A} 1 \mathrm{~B}$ and $\mathrm{B} 1$ scenarios, while the frequency of occurrence of small floods under the A2 scenario was less than that under the $\mathrm{A} 1 \mathrm{~B}$ and $\mathrm{B} 1$ scenarios.

\section{Conclusions}

In this study, the GEV, GPD, and Gamma distribution models and Copula functions were applied to estimate extreme hydrological events from 1969 to 2009 in the water source area of the middle route of South-to-North Water Diversion Project in China. Based on the simulated results of 23 GCMs from the World Climate Research Programme's CMIP3 single-model dataset in the Intergovernmental Panel on Climate Change Fourth Assessment Report, the future extreme hydrological events from 2016 to 2100 were simulated 


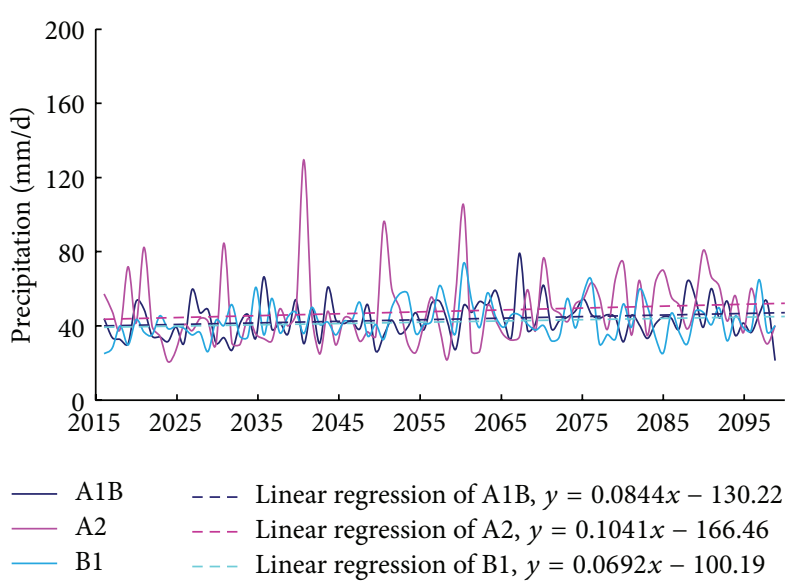

(a)

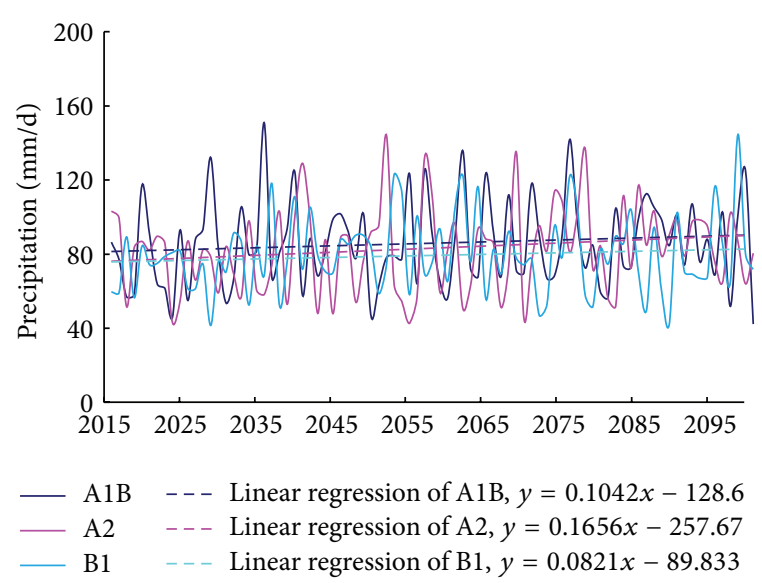

(b)

FIGURE 9: Extreme precipitation changes from 2016 to 2100 under three climate change scenarios: (a) RX1day and (b) RX3day.

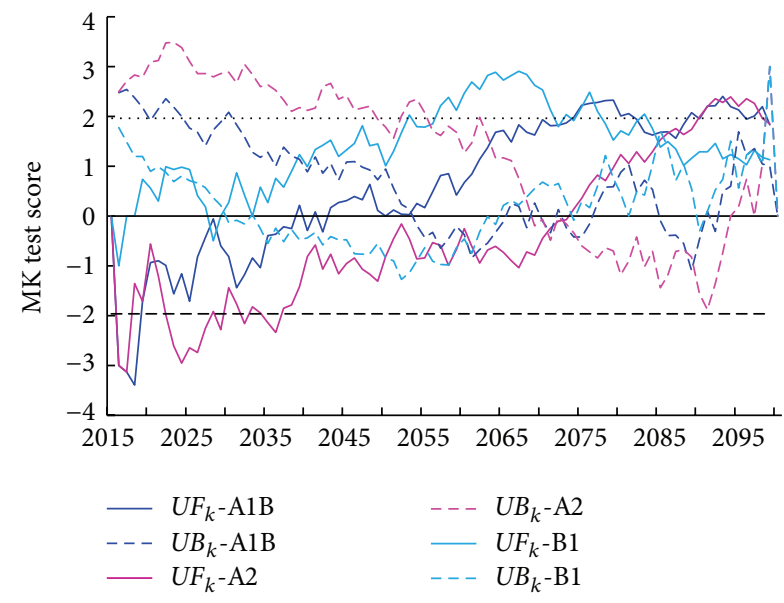

(a)

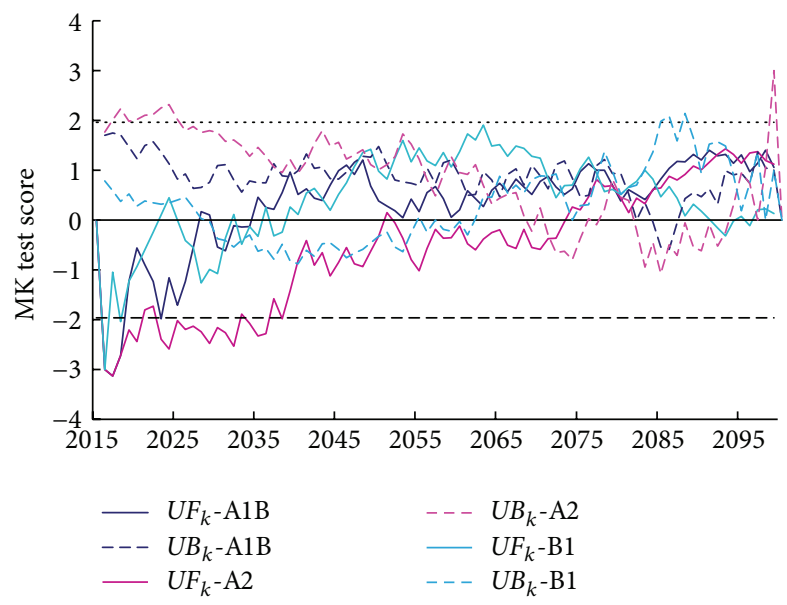

(b)

FIgURE 10: The MK test score of extreme precipitation from 2016 to 2100 under three climate change scenarios; (a) RX1day, (b) RX3day.

under the $\mathrm{A} 1 \mathrm{~B}, \mathrm{~A} 2$, and $\mathrm{B} 1$ scenarios. The main conclusions can be summarized as follows:

(1) For the AM (annual maximum) series, the GEV and Gamma model better simulated the extreme precipitation and flood volume distributions than the GPD model, while the GPD model was the best fit for the POT (peaks over threshold) series.

(2) For the 2D (two-dimensional) joint distributions of precipitation and flood volume, the Frank Copula performed better in simulation of the AM series and the corresponding GEV distribution, whereas the Gumbel Copula was the most appropriate function to simulate the POT series and the corresponding GPD distribution. The estimated extreme precipitation and flood discharges of the AM series were larger than those of the POT series for the same return period. Adopting the more conservative estimates of the AM series would provide lower risk for flood planning.
(3) For the same return period, the magnitudes of the design floods calculated by the $2 \mathrm{D}$ and $3 \mathrm{D}$ (threedimensional) Copula functions were larger than those used in the preliminary design stage of Danjiangkou Reservoir. The joint distributions utilize more of the available extreme information, and the higher estimated flood magnitudes carry lower risk for design purposes, suggesting that multivariate statistical analysis has benefits over a traditional univariate approach.

(4) The outputs of CSIRO_MK3_5 global climate model were applied to simulate the future precipitation over the study area from 2016 to 2100 . The results suggested that the future precipitation shows no significant trend under the three climate change scenarios, but the extreme precipitation showed a tendency that it will decrease in the first few years and increase in the last few years under these three scenarios, which indicated that the proportion of the extreme precipitation in total precipitation increases constantly. 


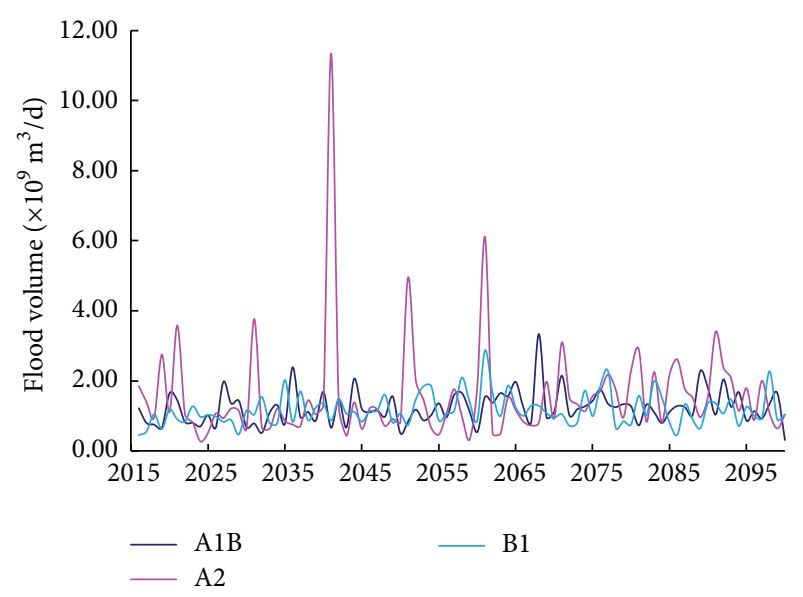

(a)

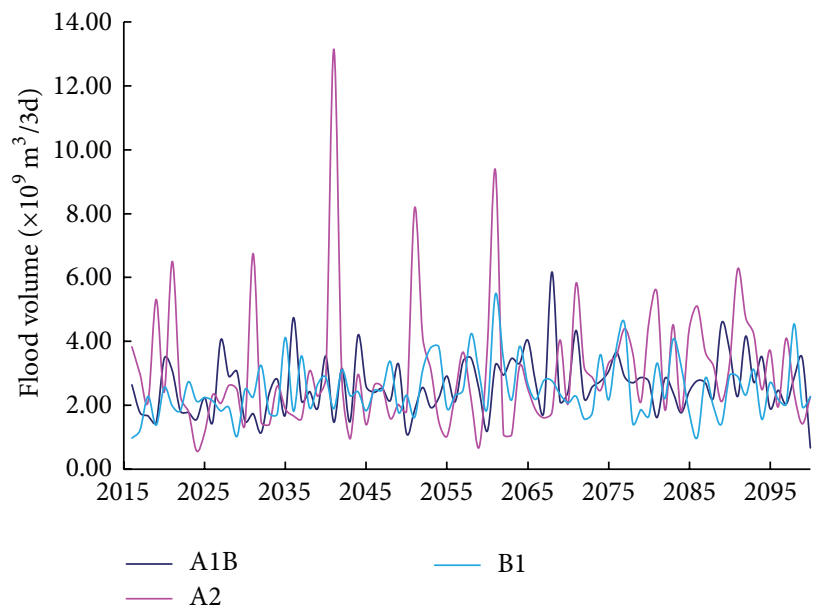

(c)

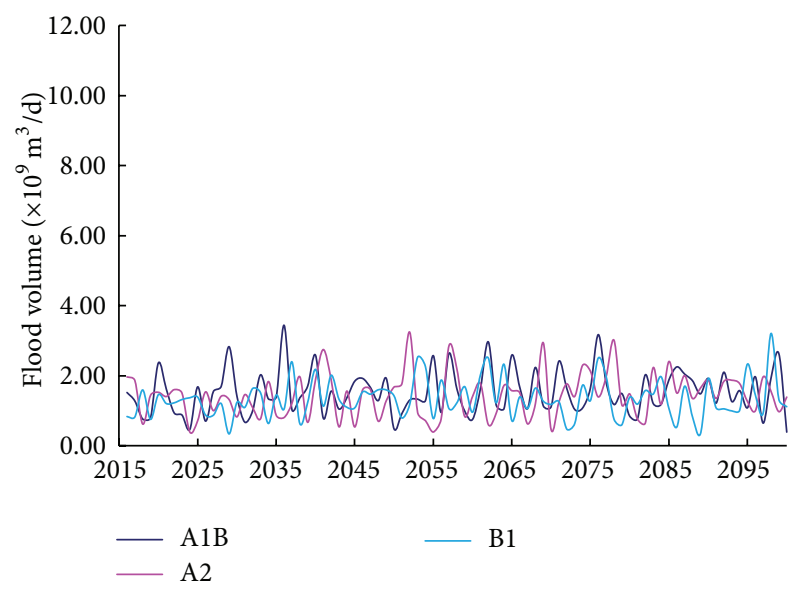

(b)

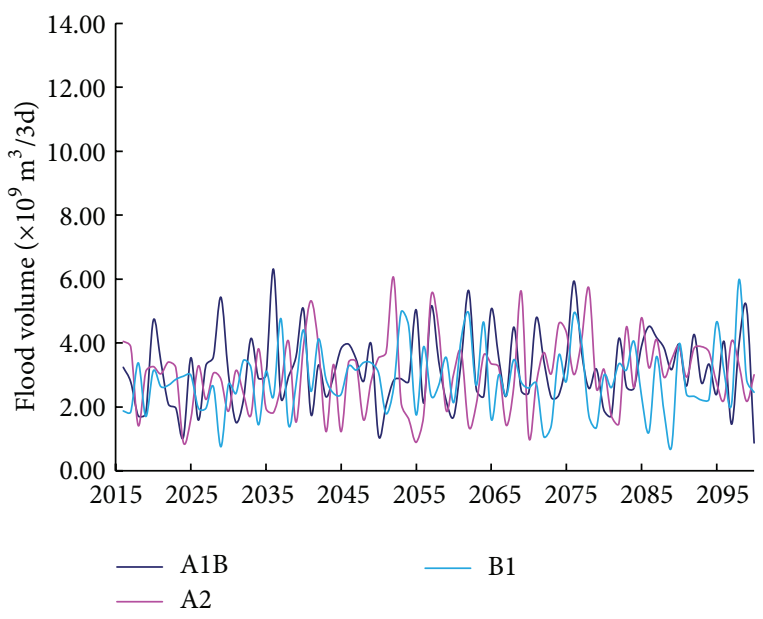

(d)

FIGURE 11: Extreme flood volume changes from 2016 to 2100 under three climate change scenarios. W1 calculated by (a) RX1day and (b) RX3day and W3 calculated by (c) RX1day and (d) RX3day.

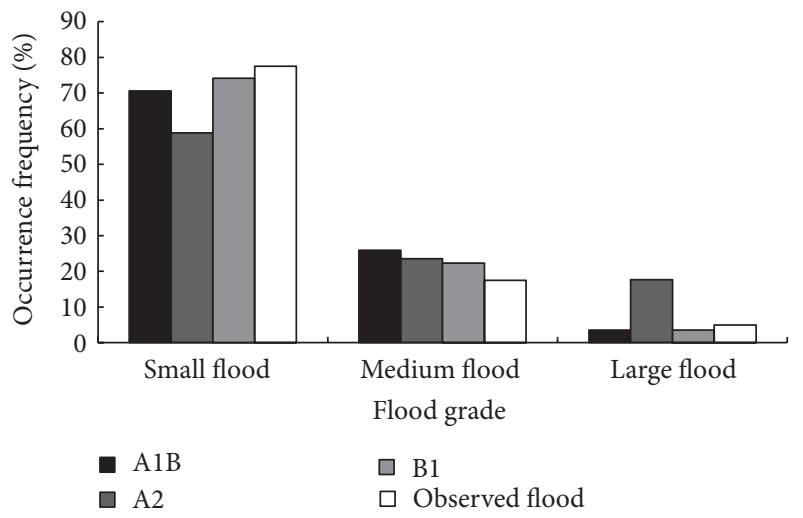

FIGURE 12: The frequency of occurrence of floods within standard size grades under three climate change scenarios and under historical conditions.

(5) The future extreme flood discharges were estimated to be slightly smaller than the historical values for the same return period, while the occurrence frequency of the medium and large floods under the future scenarios is higher than the observed occurrence frequency. The frequency of occurrence of the large flood under the A2 scenario is higher than that under the $\mathrm{A} 1 \mathrm{~B}$ and $\mathrm{B} 1$ scenarios, while the frequency of occurrence of the small flood under A2 scenario is less than that under the $\mathrm{A} 1 \mathrm{~B}$ and $\mathrm{B} 1$ scenarios.

\section{Conflict of Interests}

The authors declare that there is no conflict of interests regarding the publication of this paper.

\section{Acknowledgments}

This study was supported by the State Key Program of National Natural Science of China (no. 51339004), the National Natural Science Foundation of China (no. 51279139), 
and the Fundamental Research Funds for the Central Universities (no. 2015213020202). The authors appreciate the constructive comments of Christopher James Gippel as well as the excellent reviews of the coordinating editor and anonymous reviewers.

\section{References}

[1] M. R. Allen and W. J. Ingram, "Constraints on future changes in climate and the hydrologic cycle," Nature, vol. 419, no. 6903, pp. 224-232, 2002.

[2] M. D. Dettinger, D. R. Cayan, M. K. Meyer, and A. E. Jeton, "Simulated hydrologic responses to climate variations and change in the Merced, Carson, and American River basins, Sierra Nevada, California, 1900-2099," Climatic Change, vol. 62, no. 1-3, pp. 283-317, 2004.

[3] T. Zhu, M. W. Jenkins, and J. R. Lund, "Estimated impacts of climate warming on California water availability under twelve future climate scenarios," Journal of the American Water Resources Association, vol. 41, no. 5, Article ID 03139, pp. 10271038, 2005.

[4] T. G. Huntington, "Evidence for intensification of the global water cycle: review and synthesis," Journal of Hydrology, vol. 319, no. 1-4, pp. 83-95, 2006.

[5] IPCC, Climate Change 2001: The Science of Climate Change. Third Assessment Report of the Intergovernmental Panel on Climate Change, Cambridge University Press, Cambridge, UK, 2001.

[6] Z. Jiang, Y. Ding, and W. Chen, "Projection precipitation extremes for the 21st century over China," Advances in Climate Change Research, vol. 3, no. 4, pp. 202-207, 2007 (Chinese).

[7] P. Zhai, X. Zhang, H. Wan, and X. Pan, "Trends in total precipitation and frequency of daily precipitation extremes over China," Journal of Climate, vol. 18, no. 7, pp. 1096-1108, 2005.

[8] Y. Hong and R. F. Adler, "Predicting global landslide spatiotemporal distribution: integrating landslide susceptibility zoning techniques and real-time satellite rainfall estimates," International Journal of Sediment Research, vol. 23, no. 3, pp. 249-257, 2008.

[9] D.-I. Müller-Wohlfeil, G. Bürger, and W. Lahmer, "Response of a river catchment to climatic change: application of expanded downscaling to Northern Germany," Climatic Change, vol. 47, no. 1-2, pp. 61-89, 2000.

[10] S. B. Dessu and A. M. Melesse, "Impact and uncertainties of climate change on the hydrology of the Mara River basin, Kenya/Tanzania," Hydrological Processes, vol. 27, no. 20, pp. 2973-2986, 2013.

[11] P. D. Jones and P. A. Reid, "Assessing future changes in extreme precipitation over Britain using regional climate model integrations," International Journal of Climatology, vol. 21, no. 11, pp. 1337-1356, 2001.

[12] V. V. Kharin and F. W. Zwiers, "Estimating extremes in transient climate change simulations," Journal of Climate, vol. 18, no. 8, pp. 1156-1173, 2005.

[13] T. Fischer, B. Su, Y. Luo, and T. Scholten, "Probability distribution of precipitation extremes for weather index-based insurance in the Zhujiang River Basin, South China," American Meteorological Society, vol. 13, no. 3, pp. 1023-1037, 2012.

[14] W. Wang, X. Chen, P. Shi, and P. H. A. J. M. van Gelder, "Detecting changes in extreme precipitation and extreme streamflow in the Dongjiang River Basin in southern China," Hydrology and Earth System Sciences, vol. 12, no. 1, pp. 207-221, 2008.

[15] L. Zhang, Y. Yang, L. Qin, Y. Duan, and Z. Yang, "Distribution of extreme precipitation events in water source area for the middle route project of south-to-north water transfer under A2, A1B, B1 scenarios," Advances in Climate Change Research, vol. 9, no. 1, pp. 29-34, 2013.

[16] J. Guo, S. Guo, H. Chen, B. Yan, J. Zhang, and H. Zhang, "Prediction of changes of precipitation in Hanjiang River basin using statistical downscaling method based on ANN," Engineering Journal of Wuhan University, vol. 43, no. 2, pp. 148152, 2010 (Chinese).

[17] R. Xu, H. Chen, and J. Guo, "Impact of climate change on hydrological extreme events in upper reaches of the Hanjiang River basin," Journal of Beijing Normal University (Natural Science), vol. 46, no. 3, pp. 383-386, 2010 (Chinese).

[18] IPCC, Climate Change 2007: The Science of Climate Change. Fourth Assessment Report of the Intergovernmental Panel on Climate Change, Cambridge University Press, Cambridge, UK, 2007.

[19] J. M. Murphy, D. M. H. Sexton, D. H. Barnett et al., "Quantification of modelling uncertainties in a large ensemble of climate change simulations," Nature, vol. 430, no. 7001, pp. 768-772, 2004.

[20] N. Nakićenović, J. Alcamo, G. Davis et al., Special Report on Emissions Scenarios: A Special Report of Working Group III of the Intergovernmental Panel on Climate Change, Cambridge University Press, Cambridge, UK, 2000.

[21] A. F. Jenkinson, "The frequency distribution of the annual maximum (or minimum) values of meteorological elements," Quarterly Journal of the Royal Meteorological Society, vol. 81, no. 348, pp. 158-171, 1955.

[22] S. Coles and L. Pericchi, "Anticipating catastrophes through extreme value modelling," Journal of the Royal Statistical Society. Series C. (Applied Statistics), vol. 52, no. 4, pp. 405-416, 2003.

[23] S. Coles, An Introduction to Statistical Modeling of Extreme Values, Springer, Berlin, Germany, 2001.

[24] J. Huang, "An index of precipitation probability for dryness/wetness analysis," Meteorological Monthly, vol. 16, no. 9, pp. $8-12,1990$.

[25] B. B. Brabson and J. P. Palutikof, "Tests of the generalized Pareto distribution for predicting extreme wind speeds," Journal of Applied Meteorology, vol. 39, no. 9, pp. 1627-1640, 2000.

[26] N. B. Roger, An Introduction to Copula, Springer, New York, NY, USA, 1999.

[27] V. P. Singh and L. Zhang, "Bivariate flood frequency analysis using the Copula method," Journal of Hydrologic Engineering, vol. 11, no. 2, pp. 150-164, 2006.

[28] B. Klein, M. Pahlow, Y. Hundecha, and A. Schumann, "Probability analysis of hydrological loads for the design of flood control systems using copulas," Journal of Hydrologic Engineering, vol. 15, no. 5, pp. 360-369, 2010.

[29] H. B. Mann, "Nonparametric tests against trend," Econometrica, vol. 13, no. 3, pp. 245-259, 1945.

[30] M. G. Kendall, Rank Correlation Methods, Griffin, 1970.

[31] M. Bayazit and B. Önöz, "To prewhiten or not to prewhiten in trend analysis?” Hydrological Sciences Journal, vol. 52, no. 4, pp. 611-624, 2007.

[32] R. Sneyers, "Climate chaotic instability: statistical determination and theoretical background," Environmetrics, vol. 8, no. 5, pp. 517-532, 1997. 
[33] Y. Yang and F. Tian, "Abrupt change of runoff and its major driving factors in Haihe River Catchment, China," Journal of Hydrology, vol. 374, no. 3-4, pp. 373-383, 2009.

[34] D. Bisai, S. Chatterjee, A. Khan, and N. K. Barman, "Application of sequential Mann-Kendall test for detection of approximate significant change point in surface air temperature for Kolkata weather observatory, west Bengal, India," International Journal of Current Research, vol. 6, no. 2, pp. 5319-5324, 2014.

[35] J. M. Moraes, G. Q. Pellegrino, M. V. Ballester, L. A. Martinelli, R. L. Victoria, and A. V. Krusche, "Trends in hydrological parameters of a southern Brazilian watershed and its relation to human induced changes," Water Resources Management, vol. 12, no. 4, pp. 295-311, 1998.

[36] F.-W. Gerstengarbe and P. C. Werner, "Estimation of the beginning and end of recurrent events within a climate regime," Climate Research, vol. 11, no. 2, pp. 97-107, 1999.

[37] T. Li, Y. Jiang, J. Yin et al., "Study on design flood of Danjiangkou Reservoir," Yellow River, vol. 32, no. 11, pp. 33-35, 2010.

[38] X. Gao, Y. Ding, and Z. Zhao, "Climate change due to greenhouse effects in China as simulated by a regional climate model partl: evaluation of the model simulations," Acta Meteorologica Sinica, vol. 61, no. 1, pp. 20-28, 2003 (Chinese).

[39] X. Shi, X. Xu, and Y. Xu, "Comparison of temperature between six hundreds stations in China and output of IPCC models," Meteorological Monthly, vol. 31, no. 7, pp. 49-53, 2005.

[40] Z. Yang, L. Zhang, L. Qin, Y. Yang, and Y. Duan, "Flood characteristics and future response analysis under the climate change of the Danjiangkou reservoir," Resources and Environment in the Yangtze Basin, vol. 22, no. 5, pp. 588-594, 2013 (Chinese). 

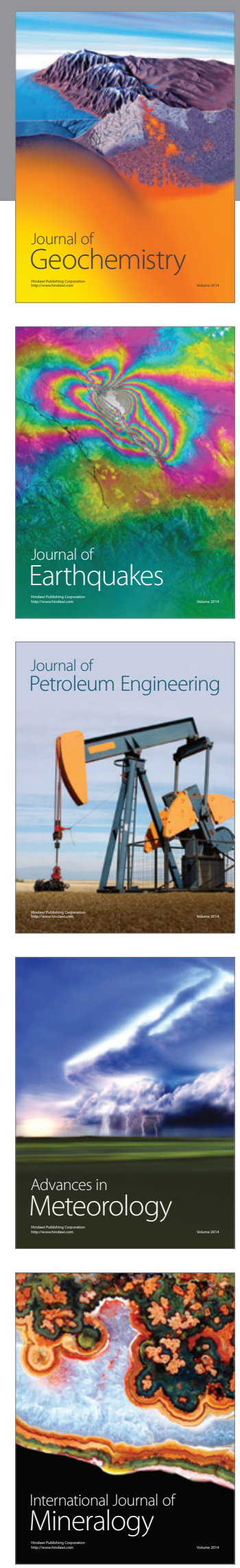
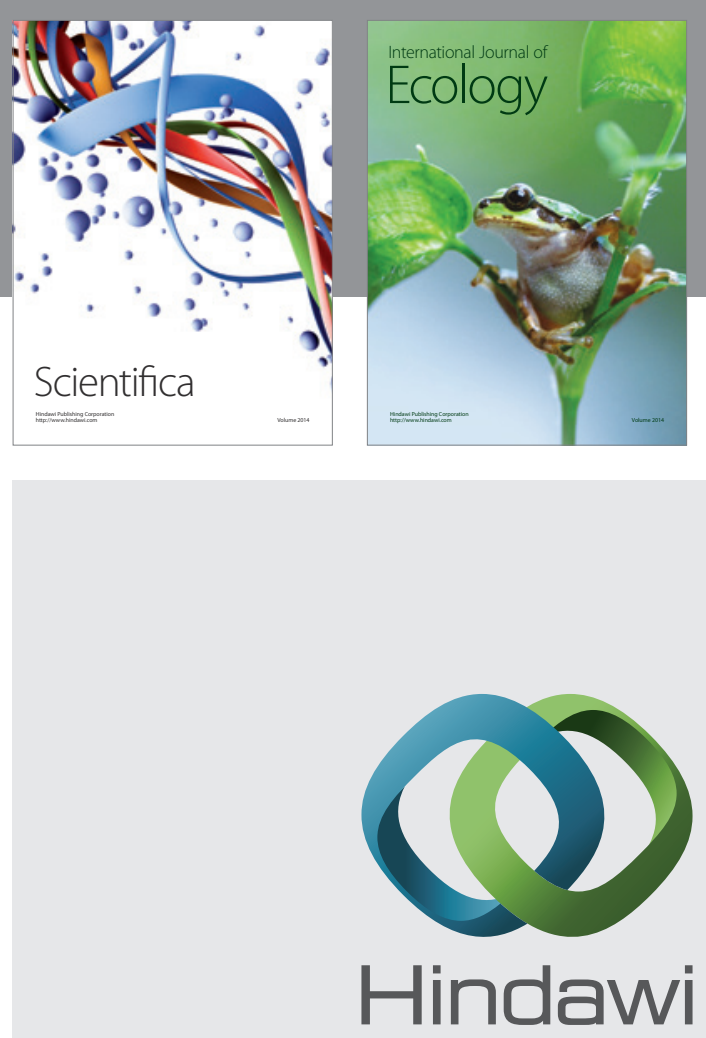

Submit your manuscripts at

http://www.hindawi.com
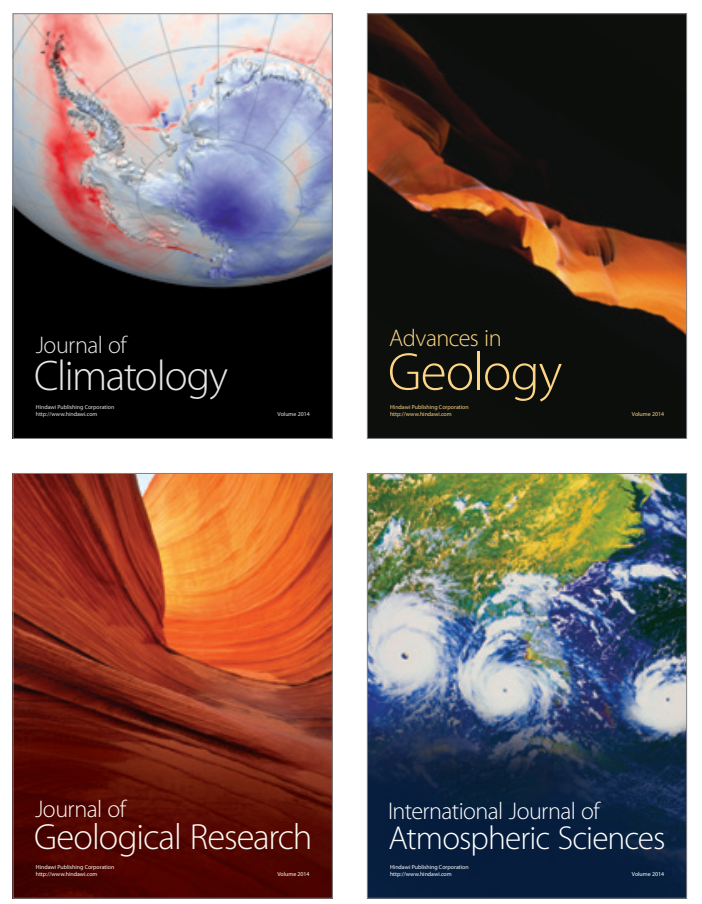

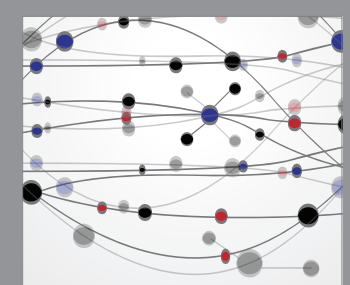

The Scientific

\section{World Journal}
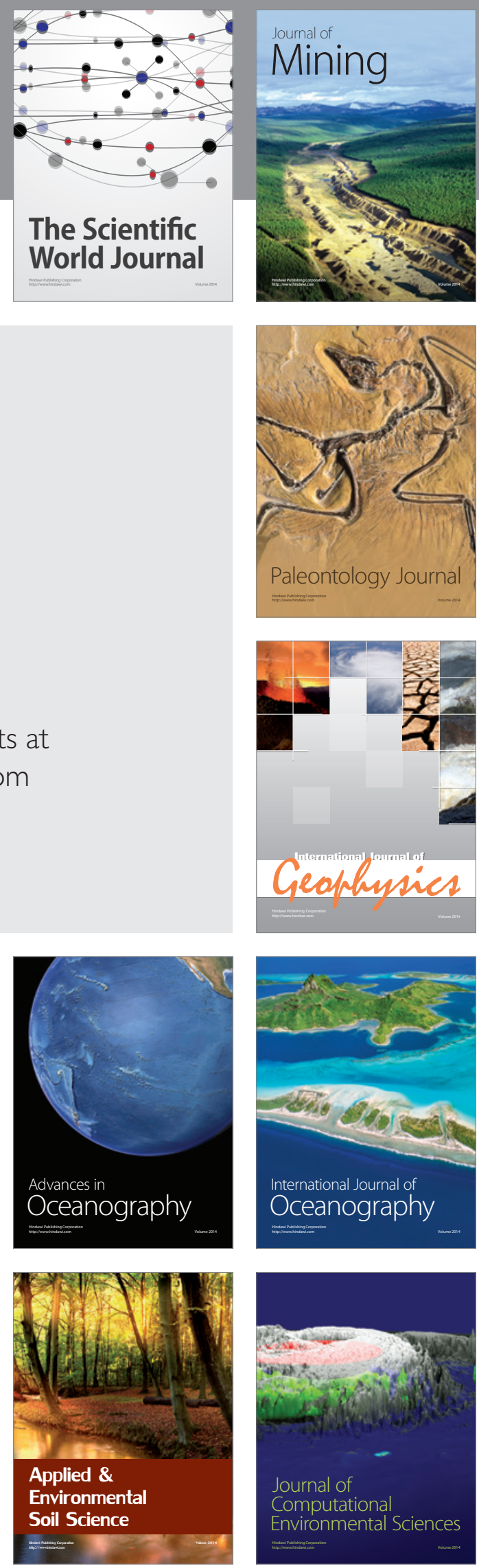